\author{
Cadernos de \\ ESTUDOS LINGǘssT(C) - (54.1), Campinas, Jan./Jun. 2012
}

\title{
HESITAÇÕES E PAUSAS COMO OCORRÊNCIAS ARTICULADAS AO MOVIMENTO DE REFORMULAÇÃO
}

\author{
MARIA FRANCISCA LIER-DEVITTO ${ }^{1}$ \\ SUZANA CARIELO DA FONSECA ${ }^{2}$
}

\begin{abstract}
RESUMO
Hesitações, pausas e reformulações estão presentes em diferentes etapas da vida dos falantes. $\mathrm{Na}$ literatura de aquisição da linguagem, tende-se a relacionar o aparecimento articulado dessas três ocorrências com um momento especial (e final) do desenvolvimento. Essas ocorrências são analisadas como reflexos da liberação da habilidade metalinguistica, ou seja, como resultado manifesto da dilatação da capacidade cognitiva de crianças (CLARK, 1978; HICKMAN, 1997 e outros). No campo das patologias da linguagem, por sua vez, a tendência dominante é tomá-las como evidência empírica de "perda" desta habilidade (LIER-DeVITTO \& FONSECA, 1997). Neste trabalho, assume-se que tais ocorrências são índices da não coincidência do falante com sua própria fala. As escansões enunciativas são interpretadas como frestas ou fendas impregnadas de carga subjetiva, mas não cognitiva. $\mathrm{O}$ foco está voltado, portanto, para a relação sujeito-linguagem, partindo das postulações: fala e sujeito não coincidem, nem tampouco falante e sujeito são instâncias coincidentes. Nessa perspectiva, produz-se um afastamento de visadas cognitivistas seja sobre o "processo de subjetivação" e de suas explicações sobre hesitações, pausas e reformulações, seja sobre a manifestação patológica da linguagem e seus efeitos subjetivos.
\end{abstract}

Palavras-chave: hesitações, pausas, reformulação.

\begin{abstract}
Hesitation, pause and reformulation permeate lifelong all speakers' speech/discourse occurrences. In the Language Acquisition field this fact is ignored and the main tendency is to relate and refer the above mentioned speech manifestations to a special and final developmental period. Under such a cognitive viewpoint, hesitation, pause and reformulation are analyzed and taken as external instantiations of a so called metalinguistic awareness. In other words, they are seen as metalinguistic abilities (CLARK, 1978; HICKMAN, 1997 e outros). Coherently enough, in the area of Speech and Language Pathology, it is argued that those articulated manifestations are empirical evidences of a metalinguistic "loss" (LIER-DeVITTO \& FONSECA, 1997). Differently, our study sustains that hesitation, pause and reformulation in speech are glaring signs of unavoidable non-coincidence between the subject-speaker and her/his own speech or discourse production. Those fluency disturbances are here understood as utterance breaches or fissures plain of subjective value - though not of a cognitive type. The theoretical assumption of the non-coincidence speaker-subject guides the discussion carried on in this article.
\end{abstract}

\footnotetext{
1. PUCSP-LAEL/DERDIC, São Paulo (SP), Brasil. e-mail: flier@uol.com.br

2.PUCSP-PEPGG/DERDIC, São Paulo (SP), Brasil. e-mail: suzfonseca@ig.com.br
} 
LIER-DEVITTO e FONSECA - Hesitações e pausas como...

We endeavored to show and sustain that hesitation; pause and reformulation are instances which give support to the statement that neither the subject-speech, nor the subject-speaker relationship can be view as steady unified block. That being the case, cognitive approaches to language development or to the subject constitution cannot be taken into account.

Keywords: hesitation, pause, reformulation

\section{INTRODUÇÃO}

As reformulações são parte integrante do processo de aquisição da linguagem e têm sido assumidas como índices relevantes do momento em que a criança é afetada pelos desacertos de seu enunciado e procura modificá-lo. Esse acontecimento, assim entendido, é uniformemente interpretado como reflexo da emergência de uma habilidade metalinguística. Segundo Vygotsky (1934/1984), esse é o momento em que é erigida uma "barreira cognitiva" que suspende o mecanicismo das produções iniciais (repetições/imitações mecânicas do outro). Trata-se do tempo da "tomada de consciência" (PIAGET, 1977). A ideia subjacente é que as crianças adquiriram a possibilidade de efetuar escolhas linguísticas e de reagir de modo adequado a uma nova situação (MARTINOT, 2000). Esta é a visão praticamente hegemônica na literatura de Aquisição da Linguagem e as investigações tendem a: (a) situar o momento em que as reformulações emergem e/ou (b) circunscrever os tipos de erros e de mecanismos mais recorrentes nas reformulações (paráfrases, reordenação, substituições locais) em períodos determinados. Há, ainda, estudos comparativos que visam à (c) definir etapas para compará-las entre línguas. Frente à natureza de pesquisas como essas, o termo "reformulação" fica, como assinalou Gürlich et alli (1983), circunscrito a uma noção meramente descritiva.

No campo das ditas patologias e terapia de linguagem, pouco se examinam tais ocorrências, embora seja inegável que elas ocorram e que as reformulações nas falas sintomáticas de crianças e/ou adultos envolvam tanto enunciados gramaticalmente corretos, quanto malogrados ${ }^{3}$. Vale considerar, portanto, que, embora insistentes, tais ocorrências não promovem, como se diz, a superação da condição sintomática. Tendo tal observação em conta, assinalamos em trabalho anterior (LIER-DeVITTO \& FONSECA,1997) que não só no caso da criança e do afásico, mas no de qualquer falante, o que se impõe é o funcionamento da língua (SAUSSURE, 1916). Recusamos, assim, a hipótese de "distância cognitiva" do falante em relação à linguagem e a noção de "apropriação" da estrutura da linguagem pelo sujeito (LIER-DeVITTO, 1998). O conceito de "captura" é introduzido e recua a hipótese cognitivista da "apropriação" (LACAN, 1949, 1960, 1964 e outros; De LEMOS, 1992, 2002, 2007). Busca-se apreender, assim, os modos de articulação da língua na fala e seus efeitos sobre o sujeitofalante(JAKOBSON, 1954).

3. Pode-se dizer que as disfluências que têm despertado algum interesse por parte dos pesquisadores deste campo têm sido unicamente aquelas identificáveis como "gagueira" (CURTI, 2009). 
A reflexão que encaminhamos neste trabalho representa um retorno à questão das reformulações na fala e uma tentativa de aprofundar o debate sobre a relação sujeito-linguagem nos campos da Aquisição, Patologias e Clínica de Linguagem.

\section{ALGUMAS (RE)CONSIDERAÇÕES TEÓRICAS}

A teorização que vem sendo desenvolvida pelo Grupo de Pesquisa Aquisição, patologias e clínica de linguagem (LAEL-Derdic/CNPq), tem forte ligação com aquela realizada no Interacionismo, proposto por De Lemos (1992 em diante), desenvolvido por ela e por outros pesquisadores. Enfatiza-se, neste ambiente teórico, o argumento empírico da "heterogeneidade" das manifestações linguísticas de crianças em processo de aquisição (De LEMOS, 1982, 2002). A heterogeneidade tem faces e todas apontam numa só direção: a de que falas de crianças, se mantidas em posição interrogante, podem ser geradoras de questões tanto sobre a fala, quanto sobre a "criança". Podemos indicar, a esse respeito, que:

(a) Há a face da heterogeneidade entre língua e fala. Ela dá, ao mesmo tempo, suporte e toma distância do axioma da Linguística, que estabelece a relação entre conhecimento e uso. Isso porque a fala (do lado do uso) atualiza o modo de operar da língua (e não um conhecimento). Nessa direção, vale lembrar que sea fala não é objeto da Linguística científica ${ }^{4}$, nela "há algo a mais ou demais, mesmo que alguma relação entre língua e fala seja reconhecível, reconhecida" (De LEMOS, comunicação pessoal)

(b) Há a face da heterogeneidade entre fala da criança e fala do adulto. Esta nos remete a discussões sobre interação, erro, estranhamento, incorporação de fragmentos e encadeamentos insólitos ${ }^{5}$.

(c) Há, ainda, a face da heterogeneidade na própria fala da criança, o que leva à problemática da subjetividade enquanto cisão o que autoriza a aproximação com a Psicanálise.

A constatação empírica da heterogeneidade tem impulsionado vigorosamente a teorização na proposta Interacionista em Aquisição da Linguagem. Colocá-la em foco é dar destaque à inquietante problemática da relação sujeito-linguagem, sujeito-alteridade. Uma afirmação de Milner (1978/1987), em O amor da língua, foi de importância fundamental para o desenvolvimento este trabalho. Ele diz:

[quando] o sujeito de desejo [incide] em um ponto [da cadeia] tudo bascula: a possibilidade de cálculo sintático cessa, a representação gramatical cede e os elementos articulados viram significantes.

e continua:

4. A "fala" fica à margem das considerações teóricas da Linguística - é matéria (empiria) ou sinal Lier-DeVitto (2005). Consultar, também, De Lemos (1998, 2002) e Milner (1978).

5. Remetemos o leitor a alguns artigos de De Lemos $(1982,1992,2002)$ e aos trabalhos dos pesquisadores reunidos no livro Aquisição, patologias e clínica de linguagem (2007). 
Esse processo (...) é o de subjetivação (...) pode operar em qualquer lugar: basta uma cadeia e um ponto que nela se distinga. O sujeito, neste sentido, tem a liberdade da indiferença (diz ele) e todos os lugares podem ser habitados pelo seu desejo (MILNER, $1978 / 1987$, p. 64).

Se, como se apreende nesta citação, a fala não é a morada/abrigo do sujeito, embora possa ser invadida por ele, é preciso reconhecer que fala (linguagem) é alteridade em relação ao sujeito ${ }^{6}$. Segundo Milner, estas "invasões" devem ser entendidas como "momentos de subjetivação". Ele diz, ainda, que eles são notáveis quando promovem perturbação na cadeia ou, como se lê na citação acima, quando a representação gramatical cede lugar a uma articulação significante. Assumir uma hipótese como esta - o que é teoricamente imperativo numa proposta como a que sustenta esta reflexão - significa admitir que o sujeito tem incidência na fala, mas não se confunde com ela. Ou seja, ele incide, "aparece", mas nela não se enlaça ou se abriga.

Seguindo este raciocínio, somos forçados a admitir que a entrada do sujeito na cadeia falada não comporta transparência, nem acomodação - ao contrário: ela é sempre perturbadora e instável uma vez que remete à necessidade enigmática de um sujeito. Desse processo de subjetivação, pensado como intrusão imprevisível do sujeito na cadeia falada, pode-se retirar que:

(1) fala e sujeito não coincidem e que

(2) falante e sujeito não são, tampouco, instâncias coincidentes.

Essas duas consequências não se coadunam com a concepção de sujeitofalante que frequenta as propostas empiristas e construtivistas da Aquisição da Linguagem. Também que o "processo de subjetivação", referido por Milner, não é o mesmo suposto na área de Aquisição da Linguagem: basta mencionar que ele (este processo) não cessa na infância. A questão é saber, então, se à parte a identificação com a Psicanálise, em sua teorização sobre o sujeito, a intermitência infindável do processo de subjetivação é passível de ser reconhecida, pelo investigador da área da Aquisição da Linguagem, no material com que ele opera.

Com o objetivo de iluminar e favorecer a discussão, reapresentamos, de início, um segmento surpreendente de um monólogo de berço de Camilla ${ }^{7}$, no qual a "projeção do eixo metafórico sobre o metonímico" estrutura e dá coesão a sequências paralelísticas em que o sentido pode fugir. Nelas, de fato, o privilégio do tecido sonoro abala o sentido ${ }^{8}$. Este segmento serve para ilustrar, ainda, a

\footnotetext{
6. Não pretendemos, neste artigo, aprofundar q questão do sujeito cindido, que remete à hipótese do inconsciente. Consideramos suficiente, para a finalidade aqui proposta, assinalar que a problemática da "heterogeneidade" e a da "não coincidência", conforme assumidas na teorização que subjaz a este artigo, envolvem reconhecer que o sujeito do inconsciente está suposto na citação acima - é sua incidência na fala que faz tudo "bascular' e "cessar" a representação gramatical. A discussão mais aprofundada demanda mais espaço e debate específico.

7. Ver Lier-DeVitto (1998) Os monólogos da criança: delírios da língua.

8. Como notaram todos os estudiosos dos monólogos que os qualificam como "ininteligíveis" (WEIR, 1962, GERNHARDT, 1993 e outros).
} 
Cadernos de Estudos Lingǘlsticos (54.1) - Jan./Jun. 2012 relação estabelecida, por Milner (1978/1987) entre "processo de subjetivação" e o fato de que "a representação gramatical cessa e cede lugar a uma articulação significante”:

1. Num fala no teu nome

2. Num fala no meu nome

3. Num fala mi danoni

4. Num fala mi danoni

5. fala mi á noni

6. fá'á mi dá nome

7. Num fala nu meu nome

8. Não $f a ́$ 'a nu ...

9. no-me/nome

10. no-me/nome

11. ........

12. $\mathbf{U} / \underline{\text { Ráfa }} \ldots$

13. Num ...

14. Rá /la no meu nome

(inspira/respira com força)

15. É da tia!

16. Eu passei rá póta!

É preciso, antes de passar os olhos sobre esse material, esclarecer o que Milner quis dizer com "cessação da representação gramatical" e "dominância da articulação significante”. A questão que aí está colocada é, precisamente, a da relação entre estrutura e acontecimento, ou melhor, do acontecimento na estrutura (LEITE, 1995). Note-se que o autor fala em "relação" e não em "eliminação/ apagamento" de um dos termos (CARVALHO, 1995). A rigor, o processo de subjetivação se serve da cadeia e, quando isso ocorre, há perturbação e "tudo pode bascular" (MILNER, 1978).

Esse processo comporta, como se vê, dois grandes efeitos mutuamente determinantes. Começamos pelo que diz respeito ao conflito entre composição/ decomposição/recomposição da substância sonora que, ao se destacar das cristalizações sígnicas, se transformam em significantes, abrindo possibilidades imprevisíveis de novas composições e, consequentemente, de significações inesperadas. É o que temos nos segmentos de (1) até (10), especialmente nos desdobramentos, "no meu nome" à "me da nome" '̀̀ "mi danone". O outro efeito remete à questão do tempo: quando há incidência do processo de subjetivação, há suspensão do tempo cronológico (da sucessão em curso) em favor da mobilidade relacional do tempo lógico, governado pela operação em que tem primazia a matéria sonora. Trata-se de tempo intervalar, de corte na cadeia falada. Um "corte" imprevisível que produz composições imprevisíveis - embora o resultado não seja indiferente já que, ali, há sujeito, há desejo. É por isso que se pode afirmar 
que as escansões na cadeia (hesitações e rupturas) são impregnadas de carga subjetiva. Elas são índices, tanto quanto os "erros", do fato de que fala e sujeito "corrompem-se mutuamente" (MILNER, 1978/1987, p. 61).

Escansões marcam, como se pode ver, a não coincidência entre a instância que fala e a que escuta (De LEMOS, 2002; entre outros). Marcam, também, a não coincidência entre a fala e aquele que fala: condição necessária para a escuta da própria fala e, portanto, para as reformulações. Como indicamos no início deste texto, o tema da não coincidência da fala da criança com a fala do outro e com a língua é um dos postulados axiais da teorização no Interacionismo. Ele afasta a ideia de interação enquanto intersubjetividade, vigente nos estudos da área, que tem na díade mãe-criança sua expressão maior (LIER-DeVITTO \& CARVALHO, 2008; LIER-DeVITTO \& FONSECA, 2008). De Lemos, abaixo, explicita seu incômodo com o nome pelo qual ficou conhecida sua proposta (e, naturalmente, com "interação") ao dizer que:

Monólogo e diálogo são palavras que vêm de outros lugares. De lugares em que a língua é território individual e, paradoxalmente, se esgota no trânsito de um indivíduo para outro (...) o termo "interacionismo" não condiz com o esforço de teorização que temos feito (...) no sentido de recuperar o que nos estudos de aquisição da linguagem tem sido ignorado ou obscurecido. A saber, as questões que a ordem própria da língua coloca para pensar, na criança, na instância subjetiva que, ainda que heterogênea à língua, nela e por ela se constitui. (De LEMOS, 1988, p. 11) (ênfase nossa).

A torção teórica imposta pela incorporação da ordem própria da língua (SAUSSURE, 1916), no Interacionismo, teve consequências: exigiu tomada de posição e direção bem específica na reflexão sobre a subjetividade, sua determinação e seus efeitos. Quanto à alteridade, sendo o outro-falante definido como "instância da língua constituída" (De LEMOS, 1992; e outros), sua falainstante não poderia ser confundida, logicamente, com uma língua - esse leque incomensurável/infinito de possibilidades enunciativas.

Várias são, então, as consequências empíricas decorrentes da assunção do postulado da heterogeneidade e da não coincidência, entre elas tem tido destaque o "erro" e/ou o "equívoco", assumido como propulsor de mudanças na fala e na escuta da criança. Há outras ocorrências que igualmente merecem ser consideradas: hesitações, rupturas e reformulações que, não menos que os desarranjos lexicais ou sintagmáticos, são índices de não coincidência de crianças com suas "próprias" falas.

Esses acontecimentos remetem a escansões ou a esgarçamentos enunciativos que afetam de modos diferentes e bem particulares a escuta do falante e a cadeia significante'. Sustentamos, neste artigo, que tais "frestas ou fendas" não

9. Ester Scarpa tem se dedicado à questão da disfluência e afirmado ser ela uma característica incontornável da fala. Certamente, hesitações e pausas são trabalhadas pela autora em profundidade sob a ótica da prosódia, da entonação. Em nosso artigo - que aborda a questão por outro ângulo, a da irrupção do sujeito nesses intervalos - não poderíamos deixar de indicar e dar reconhecimento a sua reflexão. Remetemos o leitor, por isso, a Scarpa 1994, 1995, 2000 e 2006. 
são silêncios ocos ou vazios de subjetividade - eles são incidências da criança na fala e, portanto, estão impregnados de carga subjetiva. Admitir que falante e sujeito correspondem a instâncias subjetivas não-coincidentes é assumir um fundamento teórico, que é logicamente decorrente ou articulado ao "encontro com a heterogeneidade" e à imprevisibilidade na fala de crianças (LEMOS, 2002, p. 44) $)^{10}$. Tal "encontro" conduziu Lemos, nos anos 1990, à Psicanálise ${ }^{11}$. Aproximação que trouxe em si a necessidade de dar consistência a menções, referências e noções incorporadas da Psicanálise (como sustenta De LEMOS). Parece-nos preciso, de fato, pressionar conceitos, colocá-los à prova da fala da criança, experimentar sua eficácia.

Interessa-nos, nesta perspectiva, dar destaque à ênfase colocada na não coincidência entre sujeito e linguagem (como alteridade). Podemos partir do que se lê abaixo sobre a natureza dos primeiros efeitos da linguagem sobre a criança:

\begin{abstract}
a despeito (...) da dependência [dos enunciados iniciais] da fala/interpretação do outro, (...) [dependência] não implica assimilação de tipo reprodutivo relativamente aos enunciados do outro. Isto é, há desde sempre uma língua em funcionamento, o que determina um processo de subjetivação, o qual, por sua vez, impede que se pense em termos de uma coincidência entre fala, da criança e a fala do outro. (De LEMOS, 2002, p. 57) (ênfase nossa).
\end{abstract}

Note-se que “dependência em relação à fala do outro" não é, segundo a autora, equivalente a reprodução. Assim, a aparente equivalência entre enunciados (da criança e do adulto) não deve cegar o investigador para a não coincidência entre eles. Aliás, o simples fato da incorporação (de falas) ser de "fragmentos" é, em si, significativo. Há o momento em que explode o que se reconhece como "fala da criança" (diferente, diversa da do adulto) até que a ilusão da homogeneidade acabe por favorecer o recobrimento da heterogeneidade e da não coincidência entre falas e falantes.

Enfim, tudo o que perturba uma cadeia falada poderia, em princípio, ser tomado como índice da relação paradoxal sujeito-alteridade. Paradoxal porque, em sendo essa relação constitutiva ela é, ao mesmo tempo, faltosa. Daí ser infindável ou perpétuo o processo de subjetivação - seja nas hesitações, em que o sujeito fica entre ecos significantes (LIER-DeVITTO, 1998), seja nas rupturas sem reformulação, em que há silêncio, abandono da palavra. No segmento apresentado, apontamos para o fato de que, nos intervalos silenciosos entre falas,

10. Pode-se apreender, sob essa declaração, ecos de críticas recorrentes à aplicação de instrumentais descritivos da Linguística; ferramentas utilizadas para medir a apreender regularidades, sempre identificadas a um quantum de conhecimento da criança sobre a língua. Segundo Cláudia Lemos, ao se voltar para a fala da criança, em vez de regularidades ela encontrou "a heterogeneidade... sob a forma de fragmentos dos enunciados precedentes do adulto, restos de expressões". A autora introduz na década de 1980, uma "metalinguagem alternativa" (De LEMOS, 1982) - os processos dialógicos.

11. Essas afetações "alicerçam tanto a recusa em "higienizar" (op. cit. 1982) a fala da criança ou a reduzi-la a um corpus" (De LEMOS, p. 2003). E, ainda, a "oposição sistemática aos movimentos adaptativos com que o investigador tende a encobrir a diferença [da fala da criança], sobrepondo uma interpretação ancorada na identificação pela via da semelhança” (De LEMOS, 2002, p. 43), 
o corpo se apresenta, ali, sob a forma de suspiros, sussurros e de pulsações rítmicas das cantigas infantis. Como se pode ver, a naturalidade do enunciado - "modo de presença do sujeito na fala" - vinha ao encontro de "embaraços" 12 nas tentativas de abordagem da "fala viva" (De LEMOS, 2003) de crianças e, também, de falas sintomáticas $^{13}$.

\section{HESITAÇÕES, PAUSAS E RETOMADAS DE EFEITO SINTOMÁTICO}

Partindo das considerações acima, passamos à discussão que envolve a presença/ausência de reformulação em falas sintomáticas. Para tal, trazemos um segmento de sessão de atendimento de um paciente afásico ${ }^{14}$ por um clínico de linguagem. O paciente procurava falar a respeito de sua conversa com o médico, na ocasião em que obteve alta do hospital:

\begin{tabular}{|l|l|}
\hline \multicolumn{1}{|c|}{ Terapeuta } & \multicolumn{1}{|c|}{ Paciente } \\
\hline $\begin{array}{l}\text { Logo o senhor ficou } \\
\text { bem e voltou prá } \\
\text { casa? }\end{array}$ & \\
\hline & $\begin{array}{l}\text { E, eu ...às vezes, o-o relo, o ... ichi! O dotô, o dotô, dô, } \\
\text { dôtor, dotor, médioco, médico. Ele falava com a-uma } \\
\text { pesss / comigo, né? A-assim: “cum tempo vai acontecer } \\
\text { isso"// Eu pensava que fosse/era ...logo bem, logo tempo. } \\
\text { É nada, é longe prá burro, viu? Num sai nada. Pensei que } \\
\text { fosse ficá uns dez dias, vinte dias. }\end{array}$ \\
\hline
\end{tabular}

Manifesta-se, na fala deste paciente, uma notável articulação paralelística (LIER-DeVITTO, 1998; JAKOBSON, 1960), marcada por um jogo de retomadas e substituições que, apesar do desarranjo textual que ele promove, não leva à perda de sentido stricto sensu. Há vaivém de segmentos, de fragmentos e truncamentos, mas há progressão com retroação, como se pode ver na notação,que fazemos abaixo, da mesma fala do paciente:

12. Esta palavra, que qualifica tão bem o tipo de incômodo ou dificuldade que advém na abordagem da fala, foi posta em circulação, nos trabalhos do Interacionismo, por Eliane Silveira (2006), que a retira de Lacan. A pesquisadora discute o trajeto da reflexão de Cláudia Lemos sobre a fala da criança. Este artigo está no livro que consta das referências bibliográficas: Aquisição, patologias e clinica de linguagem.

13. Essa discussão está presente nos trabalhos dos pesquisadores do Grupo de Pesquisa em Aquisição de Linguagem da UNICAMP, nos do Grupo de Pesquisa Aquisição, patologias e clínica de linguagem, LAEL-PUCSP. Ênfase deve ser dada à reflexão de Carvalho (1995, e outros), da UFPE. Faria (2001) também tangencia o tema por outro ângulo: o da relação corpo-linguagem.

14. A afasia se apresenta como uma condição sintomática tripla (FONSECA, 2002, 2009): há um "cérebro ferido", há uma "fala em sofrimento" e há um "drama subjetivo" instaurado pelo efeito que essa fala produz na escuta do próprio afásico. Colocar o problema nesses termos é indicar que a etiologia da afasia não esgota a questão (HENRY, 1992): nem sobre a linguagem, nem sobre o sujeito. 


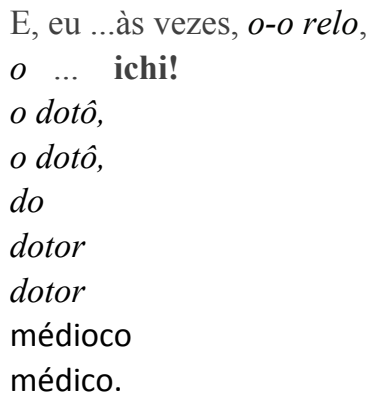

Ele falava com a

uma pess

comigo ... a-assim:

cum tempo vai acontecer isso

Eu pensava que fosse

$$
\begin{aligned}
& \text { era ... logo bem } \\
& \text { logo tempo. }
\end{aligned}
$$

É nada, é longe prá burro, viu? Num sai nada!

Pensei que fosse ficá uns dez dias,

vinte dias.

Nesse (des)arranjo manifesto na cadeia significante, reconhece-se o mecanismo de projeção do eixo metafórico sobre o metonímico (JAKOBSON, 1954, 1960), ou a operação metafórica in praesentia(LIER-DeVITTO, 1998). Mais apropriado seria invocar a homonímia como aquele movimento que representa a báscula, já que ela responde precisamente pelo fato de que palavras e sequências de palavras podem ser desfeitas e refeitas (como vimos no segmento de Camilla e, também, com efeito diferente, no do paciente acima).

Trata-se de uma "sintagmática em ato" (Milner, 2002), de arranjos e desarranjos que acontecem, digamos, "à luz do dia", ali mesmo, numa presença, sem disfarces, na cadeia sintagmática: "é essa homonímia que, suspenso ou adiado esse efeito retroativo, irrompe como texto/tecido em lugares tão díspares como nas formações do inconsciente, em certos fenômenos elementares da psicose" (De LEMOS, 2005). Acrescentaríamos que ela aparece em falas sintomáticas de afásicos, contorcidas e esburacadas, e ameaçam o sentido corriqueiro e esperado na comunicação. A homonímia é a báscula por fazer da língua um espaço, por excelência, da equivocidade.

No caso do segmento do afásico acima apresentado, a sequenciação do dizer (ainda que desajeitada) parece depender de sua retomada. É nesse modo de retorno sobre si mesma que a textualidade vai se montando por entre os efeitos da fala na escuta do falante, que busca sustentar um "querer dizer". É preciso, ainda, chamar a atenção para o fato de que, "preso" no movimento dessa fala truncada, o paciente volta a ela porque escuta sua impotência verbal (ichi!! Não sai nada!). Esse falante, portanto, não é indiferente ao modo como os significantes se articulam na sua fala - o que responde, também, pelas hesitações e pausas que nela se apresentam. 
LIER-DEVITTO e FONSECA - Hesitações e pausas como...

Vejamos, agora, um segmento de sessão de atendimento de outro paciente, também afásico. Ele e a terapeuta falavam sobre a reabertura do teatro da PUCSP, depois de uma reforma motivada por um incêndio:

\begin{tabular}{|l|l|}
\hline \multicolumn{1}{|c|}{ Terapeuta } & \multicolumn{1}{c|}{ Paciente } \\
\hline Aí, no dia 22 de agosto/ & \\
\hline & É, é isso! \\
\hline Eles reabriram & \\
\hline & É, é, muito bom! \\
\hline $\begin{array}{l}\text { E você sabe porque que foi no dia 22 de agosto } \\
\text { que eles escolheram para reabrir? }\end{array}$ & \\
\hline & Não. \\
\hline Porque dia 22 de agosto é dia da PUC. & \\
\hline & $\begin{array}{l}\text { Ah ...puco. Não! A puco, não! Mais ou menosé } \\
\text {...a puco, não! }\end{array}$ \\
\hline PUC. & \\
\hline & A puco ...não!Tá loco!! \\
\hline
\end{tabular}

Como se vê, a despeito da gravidade da menifestação sintomática, de sua condição precária de falante, o paciente faz incidência na fala: se apresenta na posição de "um outro" afetado por um dizer que o interroga, que o divide. Deslocado da posição de quem produz para a de quem escuta, ele recusa o que vem à tona (“não!”) e lamenta sua condição de falante: "mais ou menos", “tá loco!". Sua escuta (intocada) não se oferece, portanto, como ponto de apoio para engendrar a mobilidade relacional que está em causa na possibilidade de ocorrência de reformulações. Como assinalamos anteriormente, esse acontecimento pode ser tomado como índice de que falante e fala são instâncias não coincidentes.

A seguir, trazemos outro segmento de sessão de atendimento fonoaudiológico na qual uma paciente afásica procurava dizer em que circunstâncias ela havia conhecido o seu marido: 
Cadernos de Estudos Lingǘsticos (54.1) - Jan./Jun. 2012

\begin{tabular}{|c|c|}
\hline Terapeuta & Paciente \\
\hline \multicolumn{2}{|l|}{ A senhora trabalhava lá, e aí? } \\
\hline & $\begin{array}{l}\text { Aí, quando acabô... assim... assim... } \\
\text { como é...? } \\
\text { João assim, como é...? } \\
\text { Assim... como é? } \\
\text { Idade, fez idade, idada... } \\
\text { João sessenta, sessenta, não! } \\
\text { Como é? [S.I.] } \\
\text { Sei lá! Xô vê... } \\
\text { Quarenta, quarenta, não! } \\
\text { Quarenta...Não! [S.I.] Xô vê... } \\
\text { A idade foi assim... dade, tá véio. } \\
\text { Foi assim, tá véio... }\end{array}$ \\
\hline \multicolumn{2}{|l|}{ Quem? } \\
\hline & João, João. Tá véio, assim... tá .... \\
\hline \multicolumn{2}{|l|}{ Ele era velho? } \\
\hline & É, sim, é ... \\
\hline
\end{tabular}

Do mesmo modo como os outros dois pacientes afásicos, essa senhora está "sob efeito" do que diz. Neste caso, tal efeito dispara uma dialogia no interior do próprio dizer: suporte para seu enunciado. Note-se aí um sujeito entre um "sim" e um "não", que se questiona sobre um "como é?": um sujeito dividido e entre ecos significantes (LIER-DeVITTO, 1998). Esse modo do sujeito de fazer incidência na fala chama atenção na afasia (FONSECA, 1995, 2002, 2006a, 2006b).

O que vemos nesses três segmentos, contudo, é a heterogeneidade das manifestações sintomáticas na afasia: no primeiro caso, o escutar-se engendra reformulações (retomada com diferençado já dito); no segundo, como vimos, há ausência de reformulação (e a fala não "sai do lugar"). Já neste último segmento, o movimento de progressão depende fundamentalmente de uma retomada de parte do que foi dito. Mas, essa fala pende mais para dispersão do que para o fechamento do dizer.

Reiteramos que, de todo modo, em todas elas, o desarranjo na articulação significante frustra uma expectativa (seja do próprio falante, seja do outro) no instante mesmo em que a fala é proferida (LIER-DeVITTO, FONSECA \& LANDI, 2007). Na afasia, a escuta para a própria fala é fonte de sofrimento (FONSECA, 2002, 2006a, 2006 b), entre muitos motivos, porque não é condição suficiente para retomar um dizer que, por qualquer razão, foi fonte de estranhamento. Note-se, então, que se o "escutar-se" é condição necessária e suficiente para engendrar reformulações numa fala dita "normal", ela não se apresenta como tal quando o que está em causa é a condição afásica.

Deve-se dizer, ainda, e finalmente, que, contudo, é em função dela que o afásico demanda o outro (o terapeuta) para escutá-lo e, de alguma forma, para dar movimento ao seu dizer para que ele não fique sempre à margem do que foi dito. Demanda que supõe uma crença do paciente na potência de uma escuta especializada, diferente da escuta do leigo: atravessada por uma teorização, é essa escuta 
LIER-DEVITTO e FONSECA - Hesitações e pausas como...

que cria uma posição para acolher o apelo de mudança que o afásico dirige ao clínico de linguagem: uma escuta que (1) possa apreender, na fala fragmentada do paciente, indícios de um texto submerso; (2) abra suporte para uma fala/interpretação (LIER-DEVITTO, FONSECA \& LANDI, 2007, p. 25).

\section{CONSIDERAÇÕES FINAIS}

As exigências teóricas, impostas pela relação sujeito-linguagem, são de extrema complexidade e remetem a questões de fundamento que foram, aqui, apenas tocadas. Dizer, de forma positiva e consistente, “o que é (uma) fala?” e, de forma consequente, “o que é um sujeito?" é tarefa nada fácil. Um dos nós da questão quando se almeja teorizar sobre a fala, parece-nos, de fato, ser a necessidade de considerar que "falante" e "fala" são instâncias não coincidentes. Isso leva a indicar que hesitações, pausas e reformulações poderão, sobre essas bases, receber um tratamento teórico e não meramente descritivo, como procuramos mostrar.

\section{REFERÊNCIAS BIBLIOGRÁFICAS}

CARVALHO, G. M. M. (1995). Erro de pessoa: levantamento de questões sobre o equívoco em Aquisição da Linguagem. Tese de doutorado, Universidade Estadual de Campinas. Inédita.

CLARK, E. (1978). 'Awareness of language': some evidence from what from what children say and do, em A. Sinclair, R. J. Jarvella e W. J. M. Levelt (eds.), The child's conception of language. Berlin: Springer-Verlag, 17:43.

CURTI, M. T. F. (2009). Reflexões sobre a gagueira infantil na relação corpo e linguagem. Tese de doutorado inédita, Universidade Estadual de Campinas, Campinas. Inédita.

DE LEMOS, C. T. G. (2007). Da angústia na infância. Revista Literal. Escola de Psicanálise de Campinas, 10: 117:126.

. (2005). Joyce com Lacan, Joyce mais Lacan, Joyce-Lacan. Apresentação no Seminário Joyce com Lacan. Dublin, Irlanda.

. (2003). Corpo e Corpus, em N. V. A. Leite (org.) Corpolinguagem: gestos e afetos. Campinas: Mercado de Letras, 21: 30.

. (2002). Das vicissitudes da fala da criança e de sua investigação. Cadenos de Estudos Linguísticos, 42: 41:70.

. (1998). Native speaker's intuitions and metalinguistic abilities: what do they have in common from the point of view of language acquisition? Cadernos de Estudos Linguísticos, 33: 5:15.

. (1992). Los processos metafóricos y metonímicos como mecanismos de cambio. Substratum,1: 121:136.

. 1982. Sobre a aquisição da linguagem e seu dilema (pecado) original, em. J. Meisel (Ed.) Aquisição da linguagem. Frankfurt, Vervuert, 1986: 11:22.

FARIA, N. (2001). A difícil aritmética do corpo e da linguagem: reflexões sobre o input e a aquisição da linguagem. Tese de doutorado inédita. Universidade Federal de Alagoas, Maceió. Inédita.

FONSECA, S. C. da, (2009). O afásico na clínica de linguagem: levantamento de questões sobre o fim do tratamento, Sandra Pavone e Yone Maria Rafaeli (orgs), Audição, Voz e Linguagem: a Clínica e o Sujeito. Cortez Editora. São Paulo, 221-234. 
(2006). O estatuto da entrevista no processo diagnóstico da afasia, em Lier-DeVitto, Maria Francisca e Arantes, Lúcia (orgs) Aquisição, Patologias e Clínica de Linguagem. São Paulo: Editora PUCSP/FAPESP, 331:340.

(2002). O afásico na clínica de linguagem. Tese de doutorado. LAEL-PUC. São Paulo. Inédita. (1995). Afasia: A Fala em Sofrimento. Dissertação de Mestrado. LAEL/PUC. São Paulo. Inédita.

FONSECA, S. C.da; VORCARO, A. (2006b). O atendimento fonoaudiológico e psicanalítico de um sujeito afásico, em Lier-DeVitto, Maria Francisca e Arantes, Lúcia (orgs) Aquisição, Patologias e Clínica de Linguagem. São Paulo: Editora PUCSP/FAPESP, 413: 442.

GERNHARDT, J. (1988). From discourse to semantics: the development of vrbal morphology and forms of self-reference in the speech of a two-year-old. Journal of child language. 15: 337-393. Cambridge, Cambridge University Press.

GÜRLICH, E.; KOTSCHI, T. (1983). Les marqueurs de reformulation paraphrastique, Cahiers de linguistique française, 5: 305:35.

HENRY, P. (1992). A Ferramenta Imperfeita: linguagem, sujeito e discurso. Editora da UNICAMP. Campinas.

HICKMAN, M. (1997). The acquisition of French as a native language: structural and functional determinants in a cross-linguistic perspective. Journal of speech language pathology and audiology, 21: 4.

JAKOBSON, R. (1960). Linguística e Poética. Linguística e Comunicação. Editora Cultrix: São Paulo. (1954). Dois Aspectos da Linguagem e Dois Tipos de Afasia, Linguística e Comunicação. Editora Cultrix: São Paulo.

LACAN, J. (1964). O campo do outro e o retorno sobre a transferência. O Seminário - XI. Jorge Zahar Editor: Rio de Janeiro, 1979.

. (1960). Subversão do sujeito e dialética do desejo no inconsciente freudiano. Escritos - tradução de Vera Ribeiro. Jorge Zahar Editor: Rio de Janeiro, 1998.

; (1949). O Estádio do espelho como formador da função do Eu tal como nos é revelada na experiência psicanalítica. Escritos - tradução de Vera Ribeiro. Jorge Zahar Editor: Rio de Janeiro, 1998.

LEITE, N. V. de A. (1995). Psicanálise e análise do discurso: o acontecimento na estrutura. Editora Campo Matêmico. Rio de Janeiro.

LIER-DEVITTO, M. F. (2005). Falas sintomáticas: um problema antigo, uma questão contemporânea, em M. Freire, M. H. Abraão, A.M. Barcelos (orgs.), Linguística Aplicada e contemporaneidade. Pontes, Campinas. 317: 346.

. (1998). Os monólogos da criança: delírios da língua. EDUC/FAPESP, São Paulo.

LIER-DEVITTO, M. F.; ARANTES, L. (2007). Aquisição, patologias e clínica de linguagem. São Paulo: EDUC/FAPESP.

LIER-DEVITTO, M. F.; CARVALHO, G. (2008). O interacionismo: uma teorização em aquisição da linguagem, em Ingrid Finger \& Ronice Müller de Quadros Teorias de Aquisição da Linguagem. Editora da UFSC, 115: 146.

LIER-DEVITTO, M. F.; FONSECA, S. C. (2008). Considerações sobre 'equívoco' e 'diálogo' na Clínica de Linguagem, em Denilda Moura (org) Os desafios da língua: pesquisas em língua falada e escrita. Editora da UFAL, Maceió. 489: 493. 
LIER-DEVITTO e FONSECA - Hesitações e pausas como... (1997). "Reformulação" ou "Ressignificação"? Cadernos de Estudos Linguísticos (33). IEL/ UNICAMP: Campinas, 51-60.

LIER-DEVITTO, M. F.; FONSECA, S. C.; LANDI, R. (2007). Vez e Voz na linguagem: o sujeito sob efeito de sua fala sintomática. Revista Kayrós, 10(1). EDUC: São Paulo. 19-34.

MARTINOT, C. (2000). La reformulation dans des productions orales de définitions et explications (enfants de classe maternalle). Tese de doutorado, Universidade de Nantèrre. Inédita.

MILNER, J. C. (2000). El périplo estructural. Editora Paidós, Buenos Aires, 2002. . (1978/1987). O amor da língua. Porto Alegre, Artes Médicas.

PIAGET, J. (1977). O Desenvolvimento do Pensamento: Equilibração das Estruturas Cognitivas. Lisboa: Dom Quixote.

SCARPA, E. (2006). (Ainda) sobre o sujeito fluente, em Maria Francisca Lier-DeVitto \& Lúcia Arantes Aquisição, patologias e clínica de linguagem. Educ/FAPESP, São Paulo. 161: 180. . (2000). O recurso a níveis prosódicos superiores na aquisição e na afasia. Revista Palavra, 6, 48-62 . (1995). Sobre o sujeito fluente. Cadernos de Estudos Linguísticos, 29. Editora da Unicamp, Campinas, p 163-184.

. (1994). Organizações rítmicas na fala inicial, em Anais do IX Encontro Nacional da Anpoll. Editora da Universidade Federal da Paraíba. João Pessoa.

SAUSSURE, F. (1916). Curso de linguística geral. São Paulo: Cultrix.

SILVEIRA, E. M. (2006). Um certo retorno a Linguística pela via da Psicanálise, em Lier-DeVitto, Maria Francisca e Arantes, Lúcia (orgs.) Aquisição, Patologias e Clínica de Linguagem. São Paulo: Editora PUCSP/FAPESP. 33: 56.

VYGOTSKY, L. (1934/1984). Linguagem e Pensamento. São Paulo: Martins Fontes.

WEIR, R. (1962). Language in the crib, Holanda: Mouton. 